\title{
Dual Flow Interaction: Scene Flow and Data Flow, Dual Interaction in Art Installations
}

\author{
José M ${ }^{\mathrm{a}}$ Alonso-Calero ${ }^{1}$, Arcadio Reyes-Lecuona ${ }^{2}$, \\ Jesus Marín-Clavijo ${ }^{1}$, and Josefa Cano-García ${ }^{1}$ \\ ${ }^{1}$ Faculty of Fine Arts, University of Málaga \\ ${ }^{2}$ Department of Electronic Technology, University of Málaga
}

\begin{abstract}
In an interdisciplinary context with regards to the experience of interaction in virtual reality art installations, we propose an analysis from the point of view of exchanges between the user and the art installation, which is produced by a dual-flow: data flow and scene flow. This dual flow is defined as a double layer which in parallel has a physical component and an abstract one, the division is between a physical interaction considered as external and the virtual as internal. The purpose is to identify and focus the relationship between materials and components of the interaction experience.
\end{abstract}

Keywords: Art installation, virtual art, interaction, physical interface, virtual reality, space, scenic, scene flow, participation, spectator-user presence.

\section{Introduction}

This communication is part of an interdisciplinary research effort involving work between artists and engineers on fields and areas we have in common. That is why we tackle the issue of materials and terminology, which may very well be defined in engineering and have a less prosaic use in the arts. In the field of art installation, the incorporation of technology has led to interest in participation and interaction, and has produced, among others, new concepts such as open book or dematerialization of art. In this paper, we show a diagram of the proposed relationship between these two areas, with different objectives and language, to reorganize aspects and components of the interaction experience.

\subsection{Duality User-Spectator}

The evolution of media and artistic expression has been responding to a natural demand by the spectator, who engages in the artistic event. His demand is implemented as an intervention in the production with the intention of being part of a work of art through a meaningful event leaving open the work of art in the process. He wants to interact and exchange his role with the artist.

\subsection{From Representation to Participation}

In the field of contemporary art, conceptual art in its reductionism, leads to the dematerialization of art where the object is voided for the live experience where 
space and time take center stage. The artistic practices of conceptual art pioneers reflected proposals with a clear attitude towards the environment and audience participation [1].

Frank Popper links the term environment to the intervention of the spectator, where time determines the spectator's participation [2].Participation as a possibility of intervention in order to alter, manipulate and transform everything. This experience is progressively built as a result of our actions in the environment. In the words of Piaget intelligence should not contemplate but instead, transform [3].From the point of view of constructivist psychology the world of experience is always, exclusively a world constructed with the concepts we produce [4]. For Peter Weibel the interactive nature of media art consists of three elements [5]: virtuality, variability and viability which correspond to how information is stored, user modification, and how everything is modified according to image behavior.

\subsection{Contextualization}

In this paper, we focus on the interaction that occurs in art installations with Virtual Reality, but understood in a broad sense [6]. We do not want to focus on the concept of the classic 3D Virtual Reality environment with which it interacts by browsing, selecting and manipulating objects [7]. We understand that this model is applicable to any art installation where, in one way or another, the spectator interacts with a physical space that has an abstract equivalent.

During the research of contrasting empirical aspects in these art installation forms we rethink the issues related to participation in the work of art and presence in the interaction.

\section{The Dual-Flow Interaction}

In the process of interaction, in addition to the physical aspect there is an element of abstraction, which is symbolic and semiotic, related to the information the user carries, what we would call cultural baggage similar to that mentioned by David Nuñez in the sense of presence in a virtual environment. David referred to it when he speaks of the user, to the extent that when the user feels he is in the virtual environment he is influenced by two things: first what comes to him through the physical stimuli and second, the life experiences he already has, his cultural baggage [8].

These two elements are present throughout the whole course of the interaction experience, through what we consider Dual Flow is composed of:

1. Data flow, which is information and data at the physical level.

2. Scene flow which moves at the abstract level.

\subsection{Scene Flow}

In the interaction experience, we believe that on the superfluous level there is a load of abstract content which we lay as a superimposed layer. In this layer of abstraction, aspects of language art and semiotic language are referenced. We defined scene flow 
as the catalyst between the user and the physical installation, which is presented through this layer of abstraction, on a psychological level. Scene flow would be the communication of abstract information.

We assume the fact that the communication between layers is straightforward, it is not necessary to be aware of the process of encoding, transmitting and decoding. It is a virtual communication, unlike data flow, that provides neither encryption or decryption, or physical transmission as direct communication, such as telepathy, between abstraction layer and the upper level which houses the physical installation and the user.

A further analysis of the same idea is done by E. Couchot, who describes the difference between internal and external interaction, external to the human-machine interaction and internal to the relationship with the virtual world elements [9]. Depending on the place of reference for the user, we can define two kinds of interaction, an internal (virtual world) and external (physical world).

Virtual reality has always sought to promote the internal interaction and minimize the external. Its classic paradigm is based on tricking the user to perceive the virtual environment as the real world. Minimizing the user's perception that this is an external interaction, its goal is to ensure that he does not realize he is interacting with devices. With that objective, a dramatic protocol is created inviting spectators on a journey to engage them in the experience [10]. In this process we must incorporate metaphors and empirical models to the artistic approach, where we discuss the use of empirical methods in the field of art.

\subsection{Data Flow}

Data flow operates in a similar way to the physical level of network protocol towers, sending packaged information that is encoded and decoded from one side to another in the process. Such codification would be the process of communication between different layers. Once coded and divided into smaller packages, information passes from one layer to another. When this information reaches the destination, it is decoded again to reach the next level.

\section{The Layers of Abstraction}

In this paper we proposed a diagram showing the location of the concepts and materials relating to the interaction. In our diagram, art and technology are at the ends, one on each side, separated by the interface which in turn divides the experience between physical interaction (external) and virtual interaction (internal), these two interactions are of two spaces : physical and virtual. Dual flow would function in the opposite way as the interface, the interface as its name says is between two sides but the flow is that which flows from one side to the other of the interface, is what flows from one space to another.

The abstraction layer is a superimposed structure where communication is on a more abstract level, speaks more of art, psychology concepts that are at a higher abstract. 


\section{Conclusions}

In summary, in this paper we intend based on the interdisciplinary subjects shared by both artists and engineers, to identify the transfer and exchange relations present in the experience of interaction and physical interaction, which are combined as follows: user - installation, physical interaction - interaction virtual, real space - virtual environment, abstract information - information data, data flow - scene flow.

Our proposal is presented through the relationship diagrams where dual flow is between the installation and the spectator, data flow moves at the reality level and has a physical and technological nature, whereas scene flow moves at the virtual level and is abstract in nature.

\section{References}

1. Popper, F.: Arte, acción y participación: El artista y la creatividad de hoy. In: Akal / Arte y Estética (ed.), Madrid, p. 21 (1989)

2. Popper, F.: Arte, acción y participación: El artista y la creatividad de hoy. In: Akal / Arte y Estética (ed.), Madrid, p. 37 (1989)

3. Piaget, J.: Psicología y epistemología. Planeta-De Agostini, S.A., Barcelona, p. 89 (1985)

4. Von-Glasersfeld, E.: Despedida de la objetividad en El ojo del observador. Contribuciones al constructivismo. Editorial Gedisa, S.A., Barcelona, p. 27 (1994)

5. Weibel, P.: La irrazonable efectividad de la convergencia metodológica del arte y la ciencia. Epifanía, Marce-lí Antúnez Roca, coord. Claudia Giannetti. In: Arte facto y ciencia (ed.) Fundación Telefonica, Madrid, p. 54 (1999)

6. Timón, E.: Los problemas epistemológicos de la realidad virtual. Congreso Internacional de Filosofía y Realidad Virtual, celebrado en Albarracín. Teruel (2002)

7. Bowman, D.A., Kruijff, E., LaViola, J.J., Poupyrev, I.: 3D User Interfaces: Theory and Practice. Addison-Wesley Professional, Boston (2004)

8. Nunez, D.: A constructionist cognitive model of virtual presence. Collaborative Visual Computing Laboratory. CS04-07-00. Department of Computer Science. University of Cape Town, August 18 (2004)

9. Gianetti, C.: Estética digital: Sintopía del arte, la ciencia y la tecnología. L’angelot. Giuliano, Gustavo, Barcelona, p .119 (2007)

10. Lorenzo, R.: Filosofia y realidad virtual. In: Moreno, C., Lorenzo, R., De-Mingo, A. (eds.) Instituto de Estudios Turolenses. Prensas Universitarias de Zaragoza, Zaragoza (2007) 